OPEN ACCESS

Edited by:

Cristoforo Scavone,

University of São Paulo, Brazil

Reviewed by:

Rodrigo Azevedo Loiola,

Université d'Artois,

France

Andrea Carranza, Consejo Nacional de Investigaciones Cientificas y Técnicas (CONICET),

Argentina

*Correspondence:

Christopher Edwards

c.edwards@ncl.ac.uk;

orcid.org/0000-0003-1025-2095

Specialty section:

This article was submitted to Cellular Endocrinology,

a section of the journal

Frontiers in Endocrinology

Received: 26 July 2021 Accepted: 27 October 2021 Published: 18 November 2021

Citation:

Edwards C, Klekot O, Halugan $L$ and Korchev $Y(2021)$ Follow Your Nose: A Key Clue to Understanding and Treating COVID-19.

Front. Endocrinol. 12:747744. doi: 10.3389/fendo.2021.747744

\section{Follow Your Nose: A Key Clue to Understanding and Treating COVID-19}

\author{
Christopher Edwards ${ }^{1 *}$, Oleksandra Klekot ${ }^{2}$, Larisa Halugan ${ }^{3}$ and Yuri Korchev ${ }^{1}$ \\ 1 Hammersmith Hospital, Imperial College, London, United Kingdom, ${ }^{2}$ Clinical Pharmacology Department, Vinnytsia National \\ Pirogov Memorial Medical University, Vinnytsia, Ukraine, ${ }^{3}$ Infection Department, Vinnytsia State Clinical Hospital \#3, \\ Vinnytsia, Ukraine
}

This paper suggests that ATP release induced by the SARS-CoV-2 virus plays a key role in the genesis of the major symptoms and complications of COVID-19. Infection of specific cells which contain the Angiotensin-Converting Enzyme 2 (ACE2) receptor results in a loss of protection of the Mineralocorticoid Receptor (MR). Local activation by cortisol stimulates the release of ATP initially into the basolateral compartment and then by lysosomal exocytosis from the cell surface. This then acts on adjacent cells. In the nose ATP acts as a nociceptive stimulus which results in anosmia. It is suggested that a similar paracrine mechanism is responsible for the loss of taste. In the lung ATP release from type 2 alveolar cells produces the non-productive cough by acting on purinergic receptors on adjacent neuroepithelial cells and activating, via the vagus, the cough reflex. Infection of endothelial cells results in the exocytosis of WeibelPalade bodies. These contain the Von Willebrand Factor responsible for micro-clotting and angiopoietin-2 which increases vascular permeability and plays a key role in the Acute Respiratory Distress Syndrome. To test this hypothesis this paper reports proof of concept studies in which MR blockade using spironolactone and low dose dexamethasone (SpiDex) was given to PCRconfirmed COVID-19 patients. In 80 patients with moderate to severe respiratory failure 40 were given SpiDex and 40 conventional treatment with high dose dexamethasone (HiDex). There was 1 death in the HiDex group and none in the SpiDex. As judged by clinical, biochemical and radiological parameters there were clear statistically significant benefits of SpiDex in comparison to HiDex. A further 20 outpatients with COVID-19 were given SpiDex. There was no control group and the aim was to demonstrate safety. No adverse effects were noted and no patient became hyperkalaemic. 90\% were asymptomatic at 10 days. The very positive results suggest that blockade of the MR can produce major benefit in COVID19 patients. Further larger controlled studies of inpatients and outpatients are required not only for SARS-CoV-2 infection per se but also to determine if this treatment affects the incidence of Long COVID.

Keywords: COVID-19, mineralocorticoid receptor, spironolactone and dexamethasone, ATP - adenosine triphosphate, anosmia and ageusia 


\section{INTRODUCTION}

Early in the course of the SARS-CoV-2 pandemic it became clear that one of the commonest symptoms was loss of smell and/or taste. Selfreported alterations in smell and taste were detailed in a meta-analysis of 3563 confirmed cases of COVID-19 (1). They found that the overall prevalence of smell or taste impairment was $47 \%$ rising to $67 \%$ in patients with more severe disease. In about $20 \%$ of patients it was an isolated presenting symptom. Han et al. (2) reviewed the pathophysiology of anosmia in upper respiratory tract infections. Many rhinovirus infections of the nasal olfactory epithelium produce post-viral anosmia which persists for weeks or months until the cell damage is repaired. Post-viral anosmia has been reported with HCoV-229E infection with the olfactory dysfunction lasting more than 6 months. This corona virus does not use ACE2 to get into cells. Conductive or obstructive anosmia is often found with the common cold virus. In comparison with these infections SARS-CoV-2 produces a type of anosmia with a much more rapid recovery. Lechien et al. (3) looked at this in 417 patients with COVID-19. Of these 357 (85.6\%) had olfactory dysfunction $(79.6 \%$ were anosmic and $20.4 \%$ hyposmic). Olfactory dysfunction persisted after the resolution of other general symptoms in $63 \%$ cases. However, of these $72.6 \%$ recovered olfactory function within the first 8 days after resolution of the other clinical features of the disease.

Given that the virus uses the ACE2 receptor to enter cells, the location of the receptor is likely to be of importance in relation to anosmia. Olfactory sensory neurons do not express genes for ACE2 but these are found in support (sustentacular) cells and in the cells of Bowman's gland in both human and mice olfactory cells (Figure 1) $(4,5)$.

As with the nose ACE2 receptors are not found in the taste bud receptor cells (6). Studies in mice found that there was an enriched subpopulation of epithelial cells expressing ACE2 in the basal region of non-gustatory filiform papillae but not in the taste buds. ACE2 is expressed in human salivary glands in the cell membrane of ducts including the interlobular excretory ducts. Both mucinous and serous acini lack ACE2 (7). The squamous epithelium of the tongue was negative for ACE2.

Thus the SARS-CoV-2 virus causes a very high incidence of anosmia and ageusia, often with no clinical evidence of an inflammatory response, but without directly infecting the olfactory nerves and taste buds. In the nose this appears to be by infecting adjacent cells. In the mouth the most likely targets would seem to be non-gustatory filiform papillae and salivary glands. This paper suggests that it is the release of ATP by cells infected by the virus that is responsible. The role that this mechanism might play in the complications of COVID-19 has been previously published (8). That work focused mainly on the role that the Mineralocorticoid Receptor might play in endothelial pathology. This paper relates more specifically to epithelial cells.

After the SARS-CoV-2 virus enters the cell using the ACE2 receptor this results in a failure of ACE2 conversion of angiotensin II to angiotensin (1-7). High levels of angiotensin II stimulate NADPH oxidase and hence produce high levels of Reactive Oxygen Species (ROS).

The key cells infected by the virus in the nose, salivary glands and in the lung (type 2 alveolar cells) (Figure 1) contain not only
ACE2 receptors but also Mineralocorticoid Receptors (MRs) and the NAD-dependent enzyme $11 \beta$-Hydroxysteroid Dehydrogenase type 2 (11 $\beta$-HSD2) which converts cortisol (compound F) into inactive cortisone (compound E) $(9,10)$.

Oxidative stress produces loss of the normal MR protective mechanism resulting in cortisol activation of the receptor in man and by corticosterone in rats $(8,11-13)$. The consequences of the loss of $11 \beta$-HSD2 were first identified in patients with apparent mineralocorticoid excess who present with severe hypertension and hypokalaemia. This can be due to a congenital deficiency of the enzyme (14) or to inhibition of the enzyme by, for example, the active component of liquorice, glycyrrhetinic acid (GE) (15). Studies in rats confirmed the remarkable importance of this protective mechanism (16). Figure 2 is a demonstration of this.

Using epithelial cells we have shown that the addition of aldosterone produced a rapid release of ATP from the basolateral aspects of the cells (18). Using Scanning Ion Conductance Microscopy (SICM) we found that aldosterone produced cell contraction and this was associated with the opening of the epithelial sodium channel (ENaC). The released ATP acted on basolateral purinergic receptors on the cell and adjacent cells. This opened calcium channels and the increase in intracellular calcium produced cell contraction. If we incubated the cells with hexokinase and glucose to consume ATP as it was released, the cells did not contract and $\mathrm{ENaC}$ did not open.

In renal epithelial cells ATP is released in a polarised manner either at the apical or basolateral surfaces for the autocrine and paracrine regulation of epithelial function. ATP has very different effects when released into the basolateral as compared to the apical compartment. Thus in vivo and in vitro experiments have shown that apical $\mathrm{P} 2$ receptors inhibit sodium reabsorption in collecting ducts (19). If ATP is acting in a paracrine way in the nose, for example, it would seem likely that both apical and basolateral release are important. A paper by Li et al. (20) suggests how this might be achieved.

They examined ATP-containing lysosomal exocytosis by astrocytes exposed to oxidative stress. The background to the experiments was the observed decrease in intracellular ATP when the cells were exposed to oxidative stress. They found that this stimulated the accumulation of ATP within the lysosomes. In untreated cells the lysosomes were around the nucleus. After addition of hydrogen peroxide they moved away towards the cell membrane. The higher the dose of hydrogen peroxide the greater the accumulation of ATP-containing lysosomes at the margins of the cell. They then showed that the release of ATP by exocytosis of the lysosomes was calcium dependent.

If this sequence predicts what is happening in nasal, salivary and alveolar epithelia then it is worth considering the following model.

1. The virus infects the epithelial cell using the ACE2 receptor for entry.

2. The loss of the ACE2 receptor results in angiotensin II stimulation of NADPH oxidase with consequent high levels of Reactive Oxygen Species (ROS).

3. The oxidative damage produced by ROS has a series of consequences including loss of the protection of the 


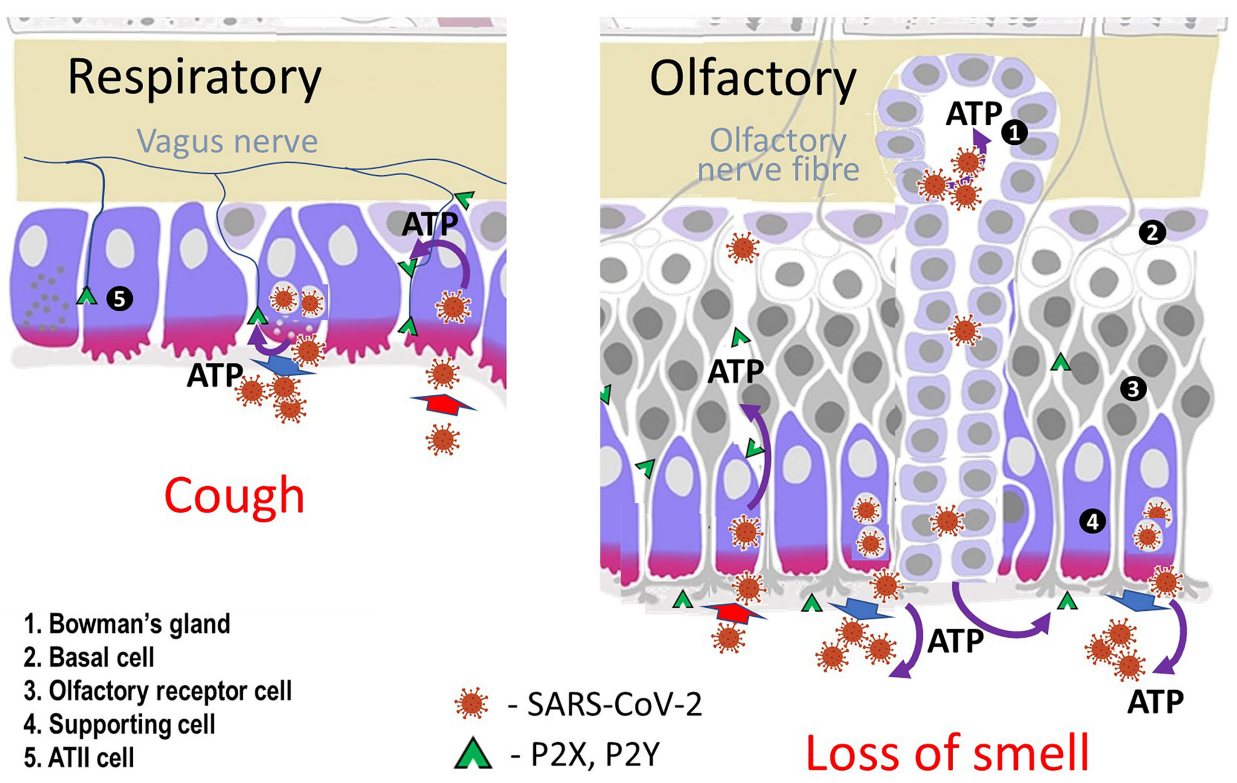

FIGURE 1 | Diagram of cells in olfactory and respiratory epithelia. Sustentacular (supporting) cells, cells lining Bowman's glands in the nose and type II alveolar cells in the lung express ACE2 receptors, Mineralocorticoid Receptors and the enzyme inactivating cortisol (11 $\beta$-HSD2).

Mineralocorticoid Receptor (MR) and activation of ATP accumulation in lysosomes. The lysosomes move to the periphery of the cell.

4. Cortisol activates the unprotected MR which stimulates the release of ATP into the basolateral compartment of the cell. This then acts on purinergic receptors which open $\mathrm{Ca}++$ channels.

5. The increase in intracellular calcium stimulates contraction of the cell and exocytosis of the ATP containing lysosomes from the apical surface of the cell with consequent high levels of extracellular ATP.

Purinergic receptors play a key role in both taste and smell $(21,22)$. ATP signalling has been shown to be crucial for communication from taste buds to gustatory nerves (23). Mice lacking P2X2 and P2X3 purinergic receptors exhibit no taste activity in chorda tympani or glossopharyngeal nerves when stimulated with taste stimuli from any of the 5 classical taste quality groups (21). Hegg et al. demonstrated that ATP released by the olfactory epithelium after noxious stimuli could act as a neuromodulatory substance independent of efferent innervation (22). They found that both P2Y and P2X receptor activation by exogenous and endogenous ATP significantly reduced odour responsiveness. Conversely purinergic receptor antagonists increased odour induced calcium transients. They concluded that ATP-mediated odour suppression is a novel mechanism for reducing olfactory sensitivity during exposure to olfacto-toxins and this might be a neuroprotective mechanism. It would appear that the SARS-CoV-2 virus might well activate this mechanism.

One of the authors (CRWE)has previously suggested that the mechanism described above for loss of smell and taste with COVID-19 is also responsible for the non-productive cough that is a common presentation in patients infected with the SARSCoV-2 virus (8). The virus enters the type II alveolar cell using the ACE2 receptor, stimulates ROS production and activates the Mineralocorticoid Receptor. ATP is released from the cell and acts on adjacent neuroepithelial bodies. This stimulates the purinergic receptors on the vagal nerve and hence the cough reflex (Figure 1).

Elevated inflammatory cytokines play an important role in the pathogenesis of severe COVID even though the evidence for a cytokine storm is debated (24). The NLRP3 inflammasome is a key part of this (25). Patients with severe COVID have elevated levels of IL-1 $\beta$ and IL-6. Activation of the inflammasome requires a two-step process with first priming and then activation (26). The priming signal increases the expression of Pattern Recognition Receptors (PRR). ROS can act as a priming signal. Extracellular ATP is a danger signal that triggers macrophage NLRP3 inflammasome by activating the purinergic P2X7 receptor (26). It is thus not surprising that infection of key cells such as type II alveolar cells leads to NLRP3 inflammasome activation (25). This raises an important question. If it was possible to lower the peri-cellular ATP levels would this inhibit the release of the NLRP3 inflammasome and hence the inflammatory response?

Experiments using endothelial cells have shown that activation of the Mineralocorticoid Receptor stimulates the release of ATP, activates purinergic receptors, increases intracellular calcium and hence exocytosis of Weibel-Palade bodies (27). These contain the Von Willebrand Factor (VWF) and angiopoietin-2. These are markedly elevated in patients admitted to hospital with COVID-19 and very high levels are predictive of death. A previous paper suggested that the release of ATP by these cells is a key mechanism underlying the exocytosis 

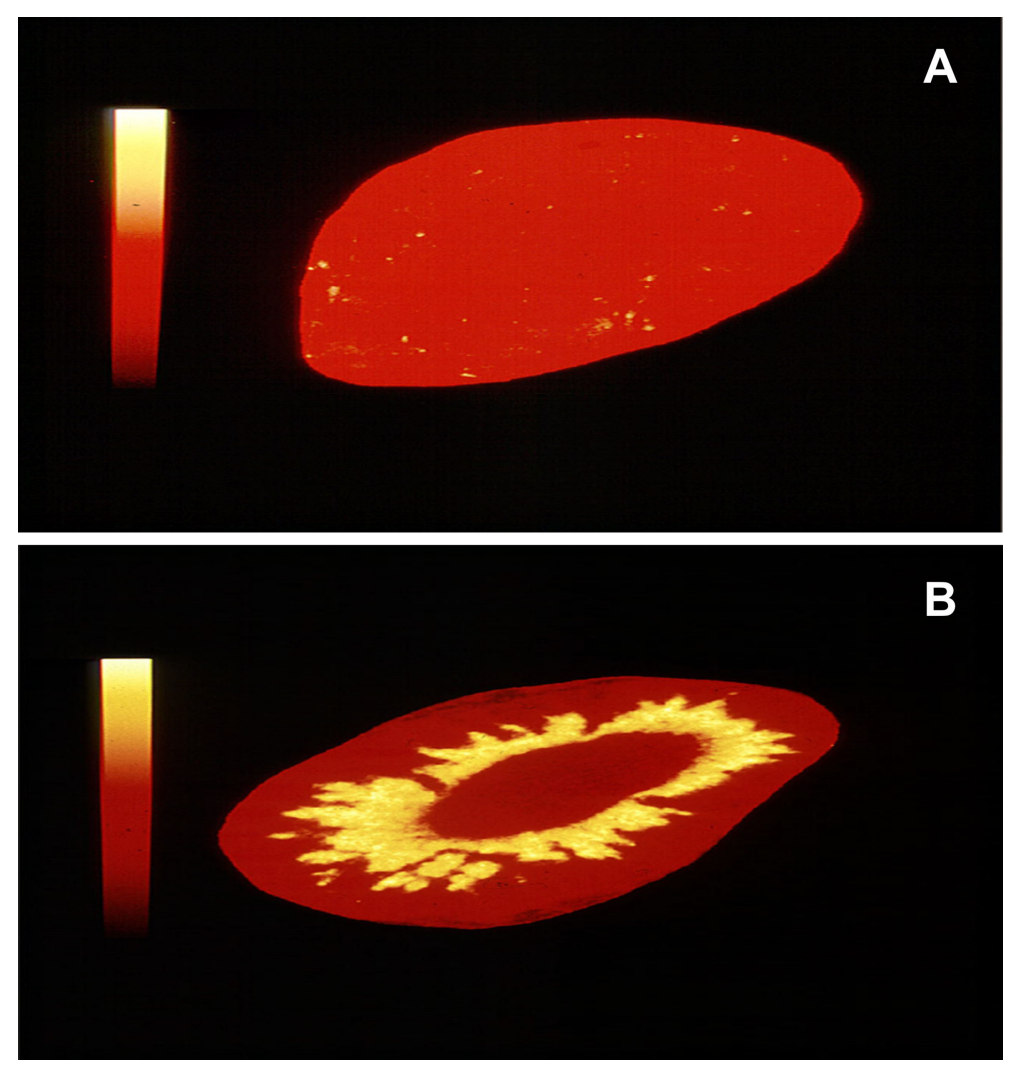

FIGURE 2 | Autoradiographs of rat kidney. In (A) ${ }^{3} \mathrm{H}$-corticosterone was given to a rat 1 hour before death. The kidneys were removed, cryostat sectioned and exposed to Ultrafilm. In (B) the experiment was repeated after simultaneous administration of both ${ }^{3} \mathrm{H}$-corticosterone and glycyrrhizic acid to inhibit $11 \beta$-HSD2 [Method of Sutanto et al. (17)]. The protected MR in rat A does not bind to the labelled corticosterone (equivalent of cortisol in man). Removal of the MR protection allows the labelled steroid to bind to the MR in the renal tubules (rat B). These autoradiographs were taken as part of previously published experiments (16).

of these molecules and hence the major complications of SARSCoV-2 infection (Acute Respiratory Distress Syndrome and multiple microthrombi) (8).

A recent study has shown that the expression of ACE2 differs markedly between endothelial and epithelial cells (28). The authors compared expression of the ACE2 protein in endothelial cells (including lung microvascular and aortic endothelium) with nasal epithelial cells. The cells were treated either with live SARS-CoV-2 or a pseudo-virus for an hour and then imaged at 24hours using post-infection luminescence. When compared to the nasal epithelial cells the endothelial cells had low or undetectable levels of ACE2 and showed no susceptibility to infection with the virus. They suggested that the vascular dysfunction and thrombosis seen in severe COVID was a result of factors released by adjacent infected epithelial cells. There is a potentially very important alternative explanation.

Kaneko et al. (29) looked at ACE2 receptor mRNA and protein expression in human microvascular cells both as a monolayer and in a 3D-printed vascular model of the middle cerebral artery which enabled them to examine the effect of shear stress. ACE2 levels were low in monolayer endothelial culture as found by others (28), in marked contrast with the 3D-model where both gene expression and protein expression levels of ACE2 progressively increased with both vessel size and flow rates. SARS-CoV-2 liposomes were found in endothelial cells in the 3D model but not in monolayer culture. Further work using a human specific intra-cranial artery stenosis model showed that ACE2 expression within the stenotic portion was notably higher than in monolayer cells. They then looked at S-protein liposomes as a way of looking at endothelial susceptibility to infection with SARS-CoV-2. They found that these labelled liposomes were bound to the endothelium primarily within the stenotic portion. This confirmed other work showing the effect of shear stress on ACE2 (30).

Of particular interest was that they coated the $3 \mathrm{D}$ models with fibronectin and then seeded them with endothelial cells. In stable blood vessels endothelial cells rest on a basement membrane consisting mainly of laminin and type IV collagen. This changes to fibronectin in unstable cells and is a key part of vascular remodelling in vascular disease (31). Thus patients with cardiovascular disease and those with diabetes have a change in their vascular basement membrane with collagen being replaced by fibronectin (31). Shear stress in these vessels produces marked activation of the NFKB pathway. All forms of 
vascular remodelling are associated with increased oxidative stress. It is thus likely that the $3 \mathrm{D}$ stenotic model and its susceptibility to infection with spike protein liposomes does reasonably explain why patients with vascular comorbidities such as hypertension, cardiovascular disease and diabetes, in addition to age-related atherogenesis, are prone to COVID-19 complications (8).

If cortisol activation of the Mineralocorticoid Receptor (MR) is playing a key role in the pathogenesis of COVID-19 and its complications it suggests that MR blockade could be an effective therapy. In this context it is vital to appreciate that free cortisol circulates at 250 times higher levels than free aldosterone. Thus, if $\mathrm{MR}$ receptor blockers alone are used they have to be given at a higher than normal dose. An alternative is to combine the MR blocking drug with dexamethasone, not as an anti-inflammatory drug, but to suppress cortisol secretion. Dexamethasone unlike cortisol does not bind to the MR. Some very important evidence suggests that MR receptor blocking drugs may be very useful in both severe and mild COVID-19.

Vicenzi et al. (32) gave canrenone intravenously to COVID-19 patients admitted to hospital with moderate to severe respiratory failure. Canrenone is a metabolite of spironolactone and has the advantage that it can be given intravenously. Out of 69 consecutive patients 39 in Group A were given conventional treatment which included methylprednisolone, hydroxychloroquine, lopinavir/ ritonavir, and anakinra. Thirty patients in Group B had this together with intravenous canrenone. The mortality in Group A was 37\% and in Group B 13\%. In Group A 47\% patients required invasive ventilation. In Group B this was only 20\%. Kaplan-Meier statistics showed that results both for all-cause mortality $(\mathrm{p}<0.005)$ and composite outcomes $(\mathrm{p}<0.0004)$ were highly significant.

Does MR receptor blockade have any effect if it is given earlier in the disease? The evidence here is limited but a paper by Lin et al. (33) is of particular interest. They gave what they called antiandrogen therapy to patients presenting early with COVID19. The anti-androgens used were spironolactone and dutasteride (a $5 \alpha$-reductase inhibitor). These drugs were given in conjunction with anti-viral drugs [azithromycin (AZI), hydroxychloroquine (HCQ), ivermectin (IVE) and nitazoxanide (NTZ)]. This was an outpatient treatment protocol using PCR tested nasal swabs. The patients did not have respiratory distress as judged by shortness of breath or oxygen saturation less than $92 \%$ and had a wide range of symptoms and not just fever, dry cough, anosmia or ageusia. Viral swabs were performed every 7 days and all patients completed clinical manifestation questionnaires on days $1 / 2 / 3$ / $7 / 14 / 30 / 60$. The primary end point was viral detection greater than 7 days and the secondary outcome the presence of symptoms greater that 7 days. 475 patients were included in the study, 223 females and 242 males. Of these 215 received spironolactone and only 28 dutasteride.

Anti-viral treatment alone in various combinations (AZI $+\mathrm{HCQ}, \mathrm{AZI}+\mathrm{HCQ}+\mathrm{IVE}, \mathrm{AZI}+\mathrm{IVE}, \mathrm{AZI}+\mathrm{NTZ})$ had no significant effect on lowering viral detection beyond 7 days, recovery in less than 7 days or symptoms lasting less than 7 days. Adding spironolactone (100mg twice daily until recovery) to AZI+HCQ significantly reduced viral detection beyond 7 days $(\mathrm{p}<0.011)$, recovery beyond 7 days $(\mathrm{p}<0.001)$ and symptoms greater than 7 days $((\mathrm{p}<0.0066)$. The most effective combination was adding spironolactone to AZI+NTZ (all p<0.0001). Unfortunately, they did not test spironolactone alone. Dutasteride also had a significant effect when given with AZI + NTZ but only 28 patients were given this. The authors suggested that the benefits of the drugs were in relation to the role of the androgen protease TMPRSS2, the cell surface protein that primes the viral spike protein and enables viral cell entry. The dose of spironolactone used is highly likely to have produced Mineralocorticoid Receptor blockade. Unfortunately, in their multivariate logistic regression of symptoms they did not include anosmia or ageusia so the effect of treatment on this was unclear.

To determine if spironolactone and low dose dexamethasone were effective in the treatment of COVID-19 we have carried out the following studies.

\section{MATERIALS AND METHODS}

\section{Study 1}

A series of 80 consecutive patients with PCR-confirmed COVID19. All patients were hospitalised for radiologically confirmed pneumonia due to SARS-CoV-2 infection and were cared for in the Vinnytsia Hospital Infection Unit. All patients received usual care treatment which included: Ceftriaxone $2 \mathrm{~g} / \mathrm{day}$ intravenously, Ambroxol $90 \mathrm{mg} /$ day orally, Enoxaparine $0.6 \mathrm{ml}$ (6000 IU subcutaneously daily).

40 patients were given dexamethasone $16 \mathrm{mg}$ orally per day for 10 days (HiDex group I) and 40 given dexamethasone $4 \mathrm{mg}$ per day and spironolactone $100 \mathrm{mg}$ per day for 10 days (SpiDex group II). Clinical characteristics, co-morbidities and clinical parameters of the patients are listed in Table 1. Patient baseline characteristics and co-morbidities were similar in both groups, age range 28-84 years.

Before treatment and after 5 days on either HiIDex (Group I) or SpiDex (Group II) body temperature, cough frequency, blood pressure, respiratory rate, and blood oxygen levels (\%) were recorded. C-reactive protein (CRP), D-dimer, and fasting blood glucose were determined at the same time. Chest X-rays were taken prior to treatment and on day 5 after starting treatment. Composite outcomes including clinical improvement, radiological evidence of pneumonia resolution or deterioration, need for invasive ventilatory support and/or all-cause inhospital mortality were noted during in-hospital follow-up.

\section{Study 2}

This was a study of the safety of treating 20 outpatients with PCR-confirmed COVID-19 without pneumonia within 2-3 days of first symptoms. They were treated with dexamethasone $4 \mathrm{mg}$ daily and spironolactone $100 \mathrm{mg}$ daily. The general characteristics, co-morbidities and clinical parameters of these patients are listed in Table 1. Based on the results of the large RECOVERY study which showed no benefit of dexamethasone 
TABLE 1 | General characteristics, clinical parameters at baseline of Study 1.

\begin{tabular}{|c|c|c|c|c|}
\hline Characteristics & Overall $(n=80)$ & Group I $(n=40 / 80)$ & Group II (n=40/80) & Group I vs group II \\
\hline \multicolumn{5}{|l|}{ General characteristics } \\
\hline Sex, females (\%) & $52(65)$ & $27(67.5)$ & $25(62.5)$ & NS \\
\hline Age, years, mean $\pm S D$ & $61.8 \pm 11.1$ & $62.4 \pm 9.8$ & $61.1 \pm 12.3$ & NS \\
\hline Hypertension, n (\%) & $53(66.3)$ & $26(65)$ & $27(67.5)$ & NS \\
\hline Ischemic heart disease, n (\%) & $55(68.8)$ & $24(60)$ & $31(77.5)$ & NS \\
\hline Diabetes, n (\%) & $20(25)$ & $10(25)$ & $10(25)$ & NS \\
\hline Obesity, n (\%) & $35(43.8)$ & $16(40)$ & $19(47.5)$ & NS \\
\hline Chronic kidney disease, n (\%) & 5 (6.3) & $2(5)$ & $3(7.5)$ & NS \\
\hline Oncopathology, n (\%) & $3(3.8)$ & $1(2.5)$ & $2(5)$ & NS \\
\hline \multicolumn{5}{|l|}{ Clinical assessment at baseline } \\
\hline Loss of smell / taste, n (\%) & $67(83.8)$ & $33(82.5)$ & $34(85)$ & NS \\
\hline Sore throat, n (\%) & $48(60)$ & $22(55)$ & $26(65)$ & NS \\
\hline Dyspnea, n (\%) & $58(72.5)$ & $30(75)$ & $28(70)$ & NS \\
\hline Dry cough, n (\%) & $68(85)$ & $36(90)$ & $32(80)$ & NS \\
\hline Fever, n (\%) & $75(93.8)$ & 38(95) & $37(92.5)$ & NS \\
\hline Need for oxygen, n (\%) & $40(50)$ & $22(55)$ & $18(45)$ & NS \\
\hline Body temp ${ }^{\circ} \mathrm{C}$, mean $\pm \mathrm{SD}$ & $37.8 \pm 0.7$ & $37.6 \pm 0.7$ & $38.0 \pm 0.7$ & NS \\
\hline BP syst., mm Hg, meanะSD & $130.6 \pm 10.0$ & $130.6 \pm 10.5$ & $137.5 \pm 22.5$ & NS \\
\hline BP diast., mm Hg mean \pm SD & $85.6 \pm 10.5$ & $86.0 \pm 8.6$ & $85.25 \pm 12.40$ & NS \\
\hline Respiratory rate/min, mean $\pm S D$ & $24.5 \pm 4.4$ & $24.8 \pm 4.6$ & $24.2 \pm 3.1$ & NS \\
\hline $\mathrm{CRP}, \mathrm{mg} / \mathrm{l}, \mathrm{mean} \pm \mathrm{SD}$ & $69.1 \pm 17.3$ & $72.4 \pm 16.7$ & $65.8 \pm 17.9$ & NS \\
\hline D-dimer, ng/ml, mean $\pm S D$ & $746.1 \pm 109.4$ & $736.7 \pm 112.6$ & $755.5 \pm 106.1$ & NS \\
\hline Fasting glucose, $\mathrm{mmol} / \mathrm{l}$, mean $\pm \mathrm{SD}$ & $6.4 \pm 1.9$ & $5.9 \pm 1.5$ & $6.9 \pm 2.2$ & NS \\
\hline$[\mathrm{K}+]$ plasma, $\mathrm{mmol} / \mathrm{l}$ & $4.29 \pm 0.36$ & $4.36 \pm 0.32$ & $4.22 \pm 0.40$ & NS \\
\hline \multicolumn{5}{|l|}{ General characteristics of Study2. } \\
\hline Characteristics & & & & Overall $(n=20)$ \\
\hline Sex, females,n (\%) & & & & $8(40)$ \\
\hline Age, years, mean $\pm S D$ & & & & $44.8 \pm 13.9$ \\
\hline Hypertension, n (\%) & & & & $5(25)$ \\
\hline Diabetes, n (\%) & & & & $2(10)$ \\
\hline Obesity, n (\%) & & & & $4(20)$ \\
\hline
\end{tabular}

SD, standard deviation; NS, Non-significant difference; mean BP, mean blood pressure; [K+] plasma, plasma concentration of potassium; CRP, C-reactive protein.

alone in patients with COVID-19 who were not on oxygen therapy or invasive ventilation we did not feel that it was ethical to have a dexamethasone alone control group. The ages of patients ranged from 21 to 58 years.

\section{Statistical Methods}

For normally-distributed demographics and clinical characteristics, data were expressed as the mean and standard deviation. Frequencies and percentages were calculated for categorical variables. The differences between the groups defined as receiving HiDex or SpiDex therapy were compared using Student's $t$ test. A $p$ value of $<0.05$ was considered to be statistically significant.

\section{Safety and Security}

All standard biosecurity and institutional safety procedures were adhered to.

\section{RESULTS}

\section{Study 1}

The results of study 1 comparing high dose dexamethasone (HiDex- Group 1) with low dose dexamethasone and spironolactone (SpiDex Group II) are shown in Table 2. This details the baseline measurements and those taken after 5 days of treatment. It was not possible to compare the two groups at 10 days as more patients had been discharged from hospital in the SpiDex as compared to the HiDex group. There was 1 death in the HiDex group and no deaths in the SpiDex group. Both groups showed improvement in their clinical parameters but this was more marked in the SpiDex group. Both groups showed a significant reduction in C-Reactive Protein and D-Dimer levels. However, the SpiDex group levels of D-Dimer were significantly lower than those with dexamethasone alone. Not surprisingly both groups had a significant elevation of their fasting blood glucose after 5 days. However, this was significantly lower in the SpiDex group as compared to the HiDex. All patients had radiological evidence of pneumonia at baseline. At 5 days 24 out of 40 patients on HiDex still had radiological changes as compared to 15 on SpiDex. Of note 5 patients in the HiDex group had radiological deterioration at 5 days in comparison to none in the SpiDex group.

\section{Study 2}

The results of the outpatient study designed to test the safety of the regimen are given in Table 2 . The classical symptoms and signs of COVID-19 were markedly improved after 5 days and at 
TABLE 2 | Study 1. Repeated measures analysis comparing changes in variables from baseline to 5 days treatment (T1).

\begin{tabular}{|c|c|c|c|c|c|}
\hline Dependent variable & Treatment group & $\begin{array}{l}\text { Mean } \\
\text { baseline }\end{array}$ & Mean T1 & $\begin{array}{c}\mathrm{p} \text {-value of comparison } \\
\text { baseline vs } \mathrm{T} 1\end{array}$ & $\begin{array}{c}\text { p-value of T1 comparison of } \\
\text { Group II vs Group I }\end{array}$ \\
\hline \multirow[t]{2}{*}{ Loss of smell/taste, $n$} & 1 & $33(82.5)$ & $30(75)$ & NS & $<0.05$ \\
\hline & $\|$ & $34(85)$ & $19(47.5)$ & $<0.05$ & \\
\hline \multirow[t]{2}{*}{ Dyspnea, n } & । & $30(75)$ & $10(25)$ & $<0.001$ & NS \\
\hline & $\|$ & $28(70)$ & $8(20)$ & $<0.001$ & \\
\hline \multirow[t]{2}{*}{ Dry cough, n } & । & $36(90)$ & $18(45)$ & $<0.001$ & NS \\
\hline & $\|$ & $32(80)$ & $12(30)$ & $<0.001$ & \\
\hline \multirow[t]{2}{*}{ Fever, n } & I & 38 (95) & $10(25)$ & $<0.001$ & NS \\
\hline & $\|$ & $37(92.5)$ & $4(10)$ & $<0.001$ & \\
\hline \multirow[t]{2}{*}{ Need for oxygen, $n$} & 1 & $22(55)$ & $7(17.5)$ & NS & NS \\
\hline & $\|$ & $18(45)$ & $5(12.5)$ & NS & \\
\hline \multirow[t]{2}{*}{ BP syst., mm Hg } & I & $130.6 \pm 10.5$ & $165.1 \pm 12.1$ & $<0.05$ & $<0.05$ \\
\hline & $\|$ & $137.5 \pm 22.5$ & $128.3 \pm 12.0$ & NS & \\
\hline \multirow[t]{2}{*}{ BP diast., mm Hg } & 1 & $86.0 \pm 8.6$ & $89.0 \pm 10.6$ & NS & NS \\
\hline & $\|$ & $85.25 \pm 12.4$ & $81.1 \pm 6.7$ & NS & \\
\hline \multirow[t]{2}{*}{ Breath rate/min } & I & $24.8 \pm 4.6$ & $18.4 \pm 3.1$ & NS & NS \\
\hline & $\|$ & $24.2 \pm 3.1$ & $16.2 \pm 1.8$ & $<0.05$ & \\
\hline \multirow[t]{2}{*}{ CRP, mg/l } & 1 & $72.4 \pm 16.7$ & $28.1 \pm 12.9$ & $<0.05$ & NS \\
\hline & $\|$ & $65.8 \pm 17.9$ & $17.1 \pm 8.7$ & $<0.05$ & \\
\hline \multirow[t]{2}{*}{ D-dimer, ng/ml } & 1 & $736.7 \pm 112.6$ & $574.8 \pm 106.4$ & NS & $<0.05$ \\
\hline & $\|$ & $755.5 \pm 106.1$ & $357.3 \pm 71.1$ & $<0.001$ & \\
\hline \multirow[t]{2}{*}{ Fasting glucose, mmol/l } & 1 & $5.9 \pm 1.5$ & $12.69 \pm 1.31$ & $<0.05$ & $<0.05$ \\
\hline & $\|$ & $6.9 \pm 2.2$ & $8.44 \pm 1.60$ & NS & \\
\hline \multirow[t]{2}{*}[\mathrm{K}+]{ plasma, mmol/l } & I & $4.36 \pm 0.32$ & $4.28 \pm 0.50$ & NS & NS \\
\hline & $\|$ & $4.22 \pm 0.40$ & $4.43 \pm 0.45$ & NS & \\
\hline
\end{tabular}

SD, standard deviation; mean BP, mean blood pressure; [K+] plasma, plasma concentration of potassium; CRP, C-reactive protein. Figures are expressed as Mean and Standard Deviation. NS, non-significant difference. No patient required ventilation: patients with oxygen saturation less than $92 \%$ given oxygen by mask.

Study 2. Repeated measures analysis comparing changes in variables from baseline to 5 days treatment (T1) and 10 days treatment (T2).

\begin{tabular}{|c|c|c|c|c|c|}
\hline Dependent variable & Mean baseline & Mean T1 & $\mathrm{p}$-value of comparison baseline vs $\mathrm{T} 1$ & Mean T2 & p-value of comparison baseline vs T2 \\
\hline Sore throat, n (\%) & $11(55)$ & $3(15)$ & $<0.05$ & 0 & $<0.001$ \\
\hline Dry cough, $\mathrm{n}(\%)$ & $16(80)$ & $11(55)$ & $<0.05$ & $2(10)$ & $<0.001$ \\
\hline Fever, n (\%) & $16(80)$ & $4(20)$ & $<0.005$ & 0 & $<0.001$ \\
\hline $\begin{array}{l}\text { PCR COVID-19 } \\
\text { positive, } n(\%)\end{array}$ & $20(100)$ & $6(30)$ & $<0.001$ & $2(10)$ & $<0.001$ \\
\hline$[\mathrm{K}+]$ plasma, $\mathrm{mmol} / \mathrm{l}$ & $4.29 \pm 0.36$ & $4.36 \pm 0.32$ & NS & $4.22 \pm 0.20$ & NS \\
\hline
\end{tabular}

$S D$, standard deviation; $[K+]$ plasma, plasma concentration of potassium; PCR polymerase chain reaction test.

10 days were almost completely resolved. Thus, only 1 patient had loss of smell and taste at 10 days as compared to 18 out of 20 at baseline. $10 \%$ had breathlessness at 10 days compared to $50 \%$ at baseline. The dry cough was a presenting feature in $80 \%$ patients but had resolved in all but $10 \%$ by 10 days. No patient became hyperkalaemic and no adverse effects were reported. There was a need for hospitalisation for 2 patients during the 10day period of our outpatient observation. Both admissions were for co-morbidities: one was for a transient ischaemic attack and the other for a urinary tract infectio)n in a patient with type II diabetes. There were no COVID-associated complications during SpiDex treatment. For reasons discussed above we did not feel that it was ethical to have a HiDex outpatient control group. However, without an untreated control group we cannot be sure what, if any, benefit ensues from this treatment.

\section{DISCUSSION}

This paper tries to explain the consequences of the SARS-CoV-2 virus infecting key cells which express ACE2 receptors, mineralocorticoid receptors and the cortisol inactivating enzyme 11ßHSD2. These cells are normally aldosterone selective but SARS-CoV-2 infection results in a loss of the specificity of the mineralocorticoid receptor protective mechanism. It is well known that the MR can be activated by normal levels of glucocorticoids when tissues are damaged by Reactive Oxygen Species generation $(12,34)$. SARS-CoV-2 by destroying the ACE2 receptor produces high levels of angiotensin II which stimulate NADPH oxidase and hence ROS production. In addition it has been shown that aldosterone induces oxidative stress in both aortic tissue and 
macrophages and that this can be blocked by MR antagonists (35)

This loss of MR selectivity allows cortisol to activate the MR and stimulate the basolateral release of ATP. The subsequent increase in intracellular calcium following purinergic receptor activation then stimulates the exocytosis of the ATP containing lysosomes. This is similar to the process that has been described for the exocytosis of Weibel-Palade bodies from endothelial cells $(18,27)$. It is suggested that the high level of extracellular ATP then acts on adjacent cells to produce loss of smell, taste and a non-productive cough. This would explain why the duration of the anosmia and ageusia in COVID-19 patients is much shorter than that seen with other viruses with cell destruction. If this is true it is likely that recovery relates to the decreased lysosomal exocytosis of ATP.

The two proof of concept studies produce important evidence that favours the hypothesis. In the first inpatient study we compared high dose dexamethasone with low dose dexamethasone and spironolactone. In the outpatient study we used low dose dexamethasone and spironolactone and had no control group given dexamethasone alone. This was on the basis of the observations made in the RECOVERY study which showed that patients with COVID-19 who were not on oxygen did not benefit from dexamethasone (36).
In the RECOVERY trial it was thought that high dose dexamethasone might have produced benefit by reducing inflammatory-based lung injury (37). If this was the main mechanism of action it might be expected that high dose dexamethasone $(16 \mathrm{mg} /$ day $)$ would have a significantly greater effect than low dose dexamethasone (4 mg/day) and spironolactone. The results of the study listed in Table 2 do not support this. Systemic inflammation as measured by Creactive Protein is strongly associated with severity and mortality in COVID-19. We found that CRP levels were lowered by high dose dexamethasone (HiDex) but that low dose dexamethasone and spironolactone (SpiDex) produced a further reduction of CRP levels. D-dimer levels were not significantly reduced by HiDex but were highly significantly reduced by SpiDex. Not surprisingly the SpiDex D-dimer results were significantly lower than HiDex. This is important given that D-dimer levels are a key measure of thrombotic activity. Patients with high D-dimer and high CRP have the greatest risk of adverse outcomes with COVID-19 (38). Part of the beneficial anti-inflammatory effect of the combination of low dose dexamethasone and spironolactone could be the result of blocking the release of the NLRP3 inflammasome via lowering extracellular ATP levels. Freeman and Swartz (25) have identified this inflammasome as a key target for the treatment of severe COVID-19 infection.

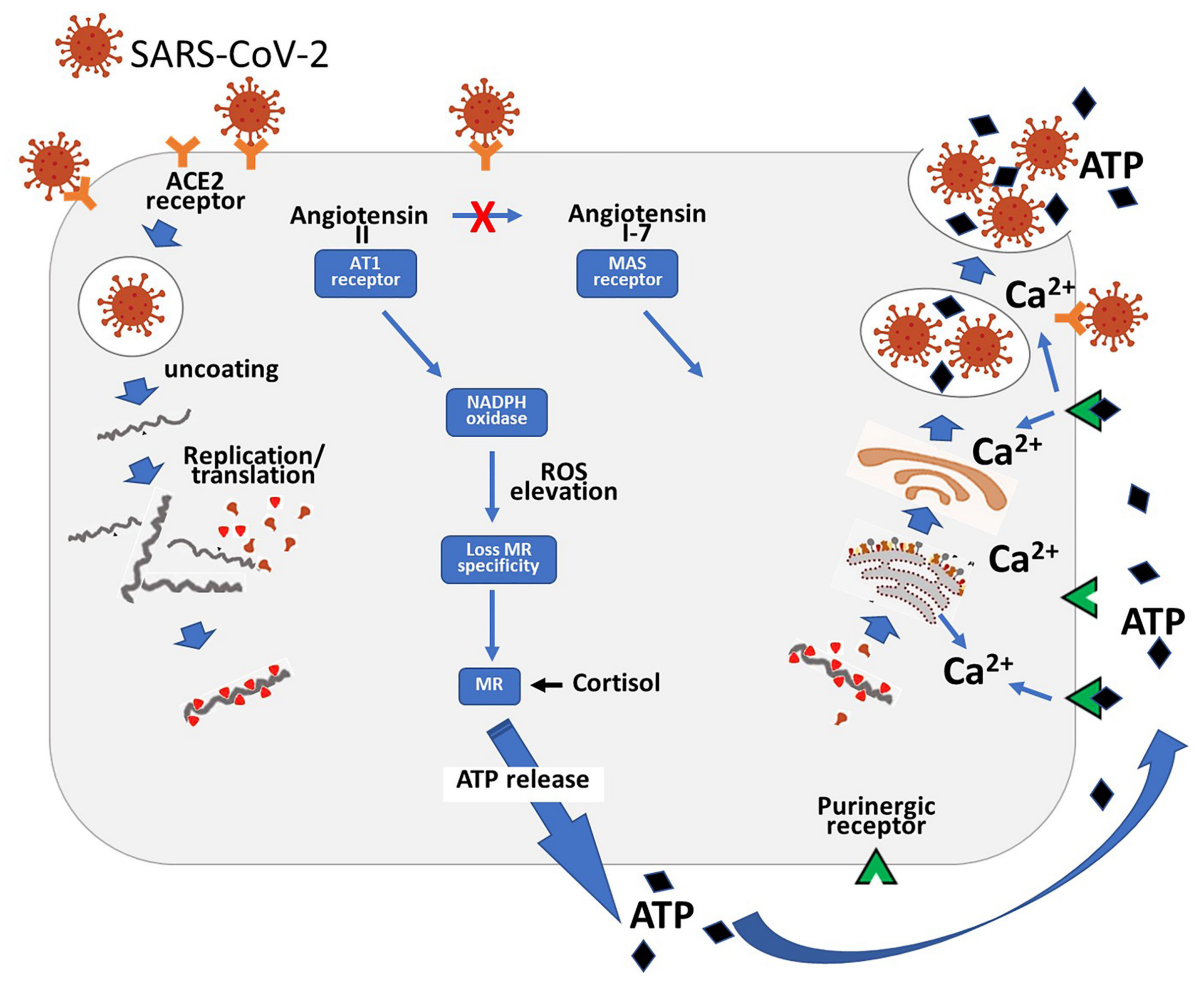

FIGURE 3 | Diagram showing the entry of the SARS-CoV-2 virus into the cell via the ACE2 receptor. Following replication of the virus it hijacks lysosomes. The high level of angiotensin II consequent on the loss of the ACE2 receptor results in ROS production with consequent loss of MR specificity. The MR is then stimulated by cortisol which stimulates basolateral release of ATP. This then acts via adjacent purinergic receptors to increase intracellular calcium. This then produces exocytosis of the ATP and viral containing lysosomes. 
If, as suggested, the non-productive cough and loss of taste and smell, the characteristic symptoms of COVID-19, are due to purinergic activation following the exocytosis of ATP then it might be thought that lowering ATP levels would have a beneficial effect. This appeared to be so. In the inpatient study cough was present in $90 \%$ of the HiDex group at baseline and in $45 \%$ at 5 days. In the SpiDex group the baseline was $89 \%$ and $30 \%$ at 5 days. The recovery of taste and smell was more striking. At baseline $82.5 \%$ of the HiDex group had anosmia/ageusia. This fell to $75 \%$ at 5 days. In the SpiDex group this was $85 \%$ at baseline and $47.5 \%$ at 5 days (significantly lower than the HiDex group). In the outpatient study $90 \%$ of the patients had loss of taste and smell at baseline but only 1 patient (5\%) had this symptom after 10 days of SpiDex treatment.

The mechanism by which the SARS-CoV-2 virus gets into cells using the ACE2 receptor has been extensively studied. Much less well understood is how the virus exits the cell. An important paper by Ghosh et al. (39) has suggested that the virus gets out of the cell not by cell lysis or the normal bio-secretory pathway but by hijacking lysosomes (Figure 3). In this process the normally acidic lysosomes are de-acidified. This change in $\mathrm{pH}$ markedly stimulates this exocytic pathway. The reason for the change in $\mathrm{pH}$ is not clear but studies have shown that angiotensin II regulates the Sodium/Hydrogen Exchanger (40). The loss of protons from the cell in exchange for sodium raises intracellular $\mathrm{pH}$. The NHE proteins 1-5 are on the cell surface. Intracellularly there is a subfamily of NHE 6-9 that are localised to the membranes of organelles including late endosomes which fuse with lysosomes. Studies have shown that lysosomal deacidification is key for the opening of the $\mathrm{pH}$ dependent calcium channel in the wall of the lysosome (41). This channel, TRPML3, is only active at neutral pH. Entry of calcium into the lysosome stimulates exocytosis.

As discussed above ATP can be released from the cell by lysosomal exocytosis. This raises a fascinating question - could inhibition of the release of lysosomes have an effect on both ATP and SARS-CoV-2 exocytosis? The evidence reviewed above demonstrates that MR blockade can inhibit the release of ATP. The results obtained by Lin et al. (33) showed that the addition of spironolactone to various combinations of anti-viral drugs

\section{REFERENCES}

1. Borsetto D, Hopkins C, Philips V, Obholzer R, Tirelli G, Polesel J, et al. SelfReported Alteration of Sense of Smell or Taste in Patients With COVID-19: A Systematic Review and Meta-Analysis on 3563 Patients. Rhinology (2020) 58 (5):1-7. doi: 10.4193/Rhin20.185

2. Han AY, Mukdad L, Long JL, Lopez IA. Anosmia in COVID-19: Mechanisms and Significance. Chem Senses (2020) 45(6):423-8. doi: 10.1093/chemse/ bjaa040

3. Lechien JR, Chiesa-Estomba CM, De Siati DR, Horoi M, Le Bon SD, Rodriguez A, et al. Olfactory and Gustatory Dysfunctions as a Clinical Presentation of Mild-to-Moderate Forms of the Coronavirus Disease (COVID-19): A Multicenter European Study. Eur Arch Otorhinolaryngol (2020) 277(8):2251-61. doi: 10.1007/s00405-020-05965-1

4. Brann DH, Tsukahara T, Weinreb C, Lipovsek M, Van Den Berge K, Gong B, et al. Nonneuronal Expression of SARS-CoV-2 Entry Genes in the Olfactory significantly reduced the time period of viral detection in nasal swabs. Unfortunately, they did not test spironolactone alone.

In addition to its conventional diuretic effect and its inhibition of exocytosis it is of interest that MR receptor antagonism with spironolactone has been shown to markedly increase the synthesis and expression of ACE2 receptors (42). If the mechanism described in this paper is true, then the duration of loss of the ACE2 receptors in specific cell types could be important. This possibility and its potential treatment with spironolactone need to be tested in the context of Long COVID.

If this hypothesis is correct then following your nose may provide an important clue as to how the SARS-CoV-2 works and also provide insight into how this very challenging condition can be treated.

\section{DATA AVAILABILITY STATEMENT}

The original contributions presented in the study are included in the article/supplementary material, further inquiries can be directed to the corresponding author.

\section{ETHICS STATEMENT}

The studies involving human participants were reviewed and approved by the University Bioethical Committee, Vinnytsia National Pirogov Memorial Medical University, Vinnytsia, Ukraine. The patients/participants provided their written informed consent to participate in this study.

\section{AUTHOR CONTRIBUTIONS}

CE - hypothesis, original clinical studies on specificity of MR, purinergic receptors, and ATP release. OK- clinical studies in Ukraine. LH - clinical studies in Ukraine. YK- laboratory studies using scanning ion conductance microscopy to study action of aldosterone. All authors contributed to the article and approved the submitted version. 
9. Kern RC, Pitovski DZ. Localization of $11 / \beta$-Hydroxysteroid Dehydrogenase: Specific Protector of the Mineralocorticoid Receptor in Mammalian Olfactory Mucosa. Acta Otolaryngol (1997) 117(5):738-43. doi: 10.3109/ 00016489709113470

10. Garbrecht MR, Klein JM, McCarthy TA, Schmidt TJ, Krozowski ZS, Snyder JM. 11- $\beta$ Hydroxysteroid Dehydrogenase Type 2 in Human Adult and Fetal Lung and its Regulation by Sex Steroids. Pediatr Res (2007) 62(1):26-31. doi: 10.1203/PDR.0b013e3180676cf3

11. Wang H, Yang P, Liu K, Guo F, Zhang Y, Zhang G, et al. Paradoxical Mineralocorticoid Receptor Activation and Left Ventricular Diastolic Dysfunction Under High Oxidative Stress Conditions. J Hypertens (2008) 26(7):1453-62. doi: 10.1097/HJH.0b013e328300a232

12. Nagase M, Matsui H, Shibata S, Gotoda T, Fujita T. Salt-Induced Nephropathy in Obese Spontaneously Hypertensive Rats via Paradoxical Activation of the Mineralocorticoid Receptor: Role of Oxidative Stress. Hypertension (2007) 50 (5):877-83. doi: 10.1161/HYPERTENSIONAHA.107.091058

13. Funder JW. Aldosterone, Mineralocorticoid Receptors and Vascular Inflammation. Mol Cell Endocrinol (2004) 217(1-2):263-9. doi: 10.1016/ j.mce.2003.10.054

14. Stewart PM, Corrie JE, Shackleton CH, Edwards CR. Syndrome of Apparent Mineralocorticoid Excess. A Defect in the Cortisol-Cortisone Shuttle. J Clin Invest (1988) 82(1):340-9. doi: 10.1172/JCI113592

15. Stewart PM, Valentino R, Wallace AM, Burt D, Shackleton CHL, Edwards CRW. Mineralocorticoid Activity of Liquorice: 11-Beta-Hydroxysteroid Dehydrogenase Deficiency Comes of Age. Lancet (1987) 330(8563):821-4. doi: 10.1016/S01406736(87)91014-2

16. Edwards CRW, Burt D, Mcintyre MA, De Kloet ER, Stewart PM, Brett L, et al. Localisation of 11B-Hydroxysteroid Dehydrogenase-Tissue Specific Protector of the Mineralocorticoid Receptor. Lancet (1988) 332(8618):986-9. doi: 10.1016/S0140-6736(88)90742-8

17. Winardi Sutanto J, van Eekelen AM, Reul JMHM, de Kloel ER. SpeciesSpecific Topography of Corticosteroid Receptor Types in Rat and Hamster Brain. Neuroendocrinology (1988) 47(5):398-404. doi: 10.1159/000124954

18. Gorelik J, Zhang Y, Sánchez D, Shevchuk A, Frolenkov G, Lab M, et al. Aldosterone Acts via an ATP Autocrine/Paracrine System: The Edelman ATP Hypothesis Revisited. Proc Natl Acad Sci U S A (2005) 102(42):15000-5. doi: 10.1073/pnas.0507008102

19. Shirley DG, Bailey MA, Unwin RJ. In Vivo Stimulation of Apical P2 Receptors in Collecting Ducts: Evidence for Inhibition of Sodium Reabsorption. Am J Physiol Renal Physiol (2005) 288(6 57-6):1243-8. doi: 10.1152/ajprenal.00152.2004

20. Li Z, Gu Y, Wen R, Shen F, Tian HL, Yang GY, et al. Lysosome Exocytosis is Involved in Astrocyte ATP Release After Oxidative Stress Induced by H2O2. Neurosci Lett (2019) 705:251-8. doi: 10.1016/j.neulet.2019.03.046

21. Eddy MC, Eschle BK, Barrows J, Hallock RM, Finger TE, Delay ER. Double P2X2/P2X3 Purinergic Receptor Knockout Mice do Not Taste $\mathrm{NaCl}$ or the Artificial Sweetener SC45647. Chem Senses (2009) 34(9):789-97. doi: 10.1093/ chemse/bjp068

22. Hegg CC, Greenwood D, Hua W, Han P, Lucero MT. Activation of Purinergic Receptor Subtypes Modulates Odor Sensitivity. J Neurosci (2003) 23 (23):8291-301. doi: 10.1523/jneurosci.23-23-08291.2003

23. Finger TE, Danilova V, Barrows J, Finger TE, Danilova V, Barrows J, et al. Communication From Taste Buds to Gustatory Nerves. Science (80- ) (2005) 310(5753):1495-9. doi: 10.1126/science.1118435

24. Sinha P, Matthay M, Calfee C. Is a "Cytokine Storm" Relevant to COVID-19? JAMA Intern Med (2020) 180:1152-4. doi: 10.1001/jamainternmed.2020.3313

25. Freeman TL, Swartz TH. Targeting the NLRP3 Inflammasome in Severe COVID19. Front Immunol (2020) 11:1518(June). doi: 10.3389/fimmu.2020.01518

26. Amores-Iniesta J, Barberà-Cremades $\mathrm{M}$, Martínez CM, Pons JA, Revilla-Nuin B, MartínezAlarcón L, et al. Extracellular ATP Activates the NLRP3 Inflammasome and Is an Early Danger Signal of Skin Allograft Rejection. Cell Rep (2017) 21(12):3414-26. doi: 10.1016/j.celrep.2017.11.079

27. Jeong Y J, Chaupin DF, Matsushita K, Yamakuchi M, Cameron SJ, Morrell $\mathrm{CN}$, et al. Aldosterone Activates Endothelial Exocytosis. Proc Natl Acad Sci U S A (2009) 106:37823787. doi: 10.1073/pnas.0804037106

28. Ahmetaj-Shala B, Peacock TP, Baillon L, Swann OC, Gashaw H, Barclay WS, et al. Resistance of Endothelial Cells to SARS-CoV-2 Infection In Vitro. bioRxiv (2020). doi: 10.1101/2020.11.08.372581
29. Kaneko N, Satta S, Komuro Y, Muthukrishnan SD, Kakarla V, Guo L, et al. FlowMediated Susceptibility and Molecular Response of Cerebral Endothelia to SARSCoV-2 Infection. Stroke (2021) 52:260-70. doi: 10.1161/STROKEAHA.120.032764

30. Song J, Hu B, Qu H, Wang L, Huang X, Li M, et al. Upregulation of Angiotensin Converting Enzyme 2 by Shear Stress Reduced Inflammation and Proliferation in Vascular Endothelial Cells. Biochem Biophys Res Commun (2020) 525(3):812-8. doi: 10.1016/j.bbrc.2020.02.151

31. Schwartz MA, Vestweber D, Simons M. A Unifying Concept in Vascular Health and Disease. Science (80- ) (2018) 360(6386):270-1. doi: 10.1126/ science.aat 3470

32. Vicenzi M, Ruscica M, Iodice S, Rota I, Ratti A, Di Cosola R, et al. The Efficacy of the Mineralcorticoid Receptor Antagonist Canrenone in COVID-19 Patients. J Clin Med (2020) 9(9):2943. doi: 10.3390/jcm9092943

33. Lin EM, Cadegiani FA, Goren A, Wambier CG. Early Antiandrogen Therapy ( EAT ) for COVID-19 With Dutasteride or Spironolactone Results in Faster Virological and Clinical Remission: A Post Hoc Analysis of 475 Patients Treated W ... Early Antiandrogen Therapy ( EAT ) for COVID-19 With Dutasteride or. Research Gate Preprint (2020) (December). doi: 10.13140/ RG.2.2.22372.19848

34. Funder JW. Mineralocorticoid Receptor Activation and Oxidative Stress. Hypertension (2007) 50(5):840-1. doi: 10.1161/HYPERTENSIONAHA. 107.098012

35. Keidar S, Kaplan M, Pavlotzky E, Coleman R, Hayek T, Hamoud S, et al. Aldosterone Administration to Mice Stimulates Macrophage NADPH Oxidase and Increases Atherosclerosis Development A Possible Role for Angiotensin-Converting Enzyme and the Receptors for Angiotensin II and Aldosterone. Circulation (2004) 109:2213-20. doi: 10.1161/01.CIR. 0000127949.05756.9D

36. Horby. Dexamethasone in Hospitalized Patients With Covid-19 Preliminary Report. N Engl J Med (2020). doi: 10.1056/nejmoa2021436

37. University of Oxford. Low-Cost Dexamethasone Reduces Death by Up to One Third in Hospitalised Patients With Severe - The RECOVERY Trial. Oxford (2021) 384:693-704.

38. Smilowitz NR, Kunichoff D, Garshick M, Shah B, Pillinger M, Hochman JS, et al. C-Reactive Protein and Clinical Outcomes in Patients With COVID-19. Eur Heart J (2021) 42:2270-9. doi: 10.1093/eurheartj/ehaa1103

39. Ghosh S, Dellibovi-Ragheb TA, Kerviel A, Pak E, Qiu Q, Fisher M, et al. $\beta$ Coronaviruses Use Lysosomes for Egress Instead of the Biosynthetic Secretory Pathway. Cell (2020) 183(6):1520-1535.e14. doi: 10.1016/ j.cell.2020.10.039

40. Peti-peterdi J, Bell PD. Regulation of Macula Densa Na:H Exchange by Angiotensin II. Kidney Int (1998) 54(6):2021-8. doi: 10.1046/j.15231755.1998.00200.x

41. Miao Y, Li G, Zhang X, Xu H, Abraham SN. A TRP Channel Senses Lysosome Neutralization by Pathogens to Trigger Their Expulsion. Cell (2015) 161 (6):1306-19. doi: 10.1016/j.cell.2015.05.009

42. Keidar S, Gamliel-Lazarovich A, Kaplan M, Pavlotzky E, Hamoud S, Hayek T, et al. Mineralocorticoid Receptor Blocker Increases Angiotensin-Converting Enzyme 2 Activity in Congestive Heart Failure Patients. Circ Res (2005) 97 (9):946-53. doi: 10.1161/01.RES.0000187500.24964.7A

Conflict of Interest: The authors declare that the research was conducted in the absence of any commercial or financial relationships that could be construed as a potential conflict of interest.

Publisher's Note: All claims expressed in this article are solely those of the authors and do not necessarily represent those of their affiliated organizations, or those of the publisher, the editors and the reviewers. Any product that may be evaluated in this article, or claim that may be made by its manufacturer, is not guaranteed or endorsed by the publisher.

Copyright (c) 2021 Edwards, Klekot, Halugan and Korchev. This is an open-access article distributed under the terms of the Creative Commons Attribution License (CC BY). The use, distribution or reproduction in other forums is permitted, provided the original author(s) and the copyright owner(s) are credited and that the original publication in this journal is cited, in accordance with accepted academic practice. No use, distribution or reproduction is permitted which does not comply with these terms. 